\title{
Controladoria pública municipal na perspectiva dos profissionais do controle externo
}

Mestrado em andamento em Contabilidade pela Universidade Federal do Paraná UFPR

Professor da Universidade Estadual do Centro-Oeste - UNICENTRO Rua Presidente Vargas, 22. Centro. Rebouças/PR. CEP: 84550-000

E-mail:wgerigk2006@yahoo.com.br

Marcelo Resquetti Tarifa Mestrado em andamento em Contabilidade pela Universidade Federal do Paraná UFPR

Professor da UNOPAR e Universidade Estadual de Londrina - UEL Rua Prof. Samuel Moura, 350, Ap 1302. Jardim Andrade. Londrina. CEP: 86061-060 E-mail:marcelotarifa@hotmail.com

Lauro Brito de Almeida Doutorado em Controladoria e Contabilidade pela Universidade de São Paulo - USP Coordenador do Programa de Mestrado em Contabilidade da UFPR Av. Visconde de Guarapuava, 4517, Ap 171. Batel. Curitiba. CEP: 80240-010 E-mail: gbrito@uol.com.br

Márcia Maria dos Santos Bortolocci Espejo Doutorado em andamento em Contabilidade e Controladoria pela Universidade de São Paulo - USP Professora da Universidade Federal do Paraná - UFPR Rua Atílio Bório, № 119 Ap. 1502. Cristo Rei. Curitiba. CEP: 80050-250 E-mail:marciabortolocci@ufpr.br

\section{RESUMO}

O propósito deste estudo é verificar a percepção dos profissionais que atuam no controle externo sobre a controladoria no ambiente público municipal, abordando aspectos organizacionais, estruturais e gerenciais. A metodologia empregada caracteriza-se quanto aos objetivos como exploratória; e os procedimentos utilizados foram pesquisas bibliográficas e de levantamento ou survey. A pesquisa foi conduzida por meio de questionário enviado aos profissionais que atuam em um órgão de controle externo na região Sul do país. Os resultados indicam que estes profissionais entendem que a controladoria no ambiente municipal deve ser tratada com um órgão de staff, que suas funções devem ter natureza gerencial e que, a implantação da controladoria municipal configura-se com uma evolução na forma de se administrar os entes públicos municipais levando tais entidades a melhorarem a aplicação dos recursos públicos existentes e, conseqüentemente, o seu desempenho. 
Controladoria pública municipal na perspectiva dos profissionais do controle externo Willson Gerigk, Marcelo Resquetti Tarifa, Lauro Brito de Almeida, Márcia Maria dos Santos Bortolocci

Palavras-chave: Controladoria. Controladoria Municipal. Controle Externo.

\section{Controlling public hall in the perspective of the professionals in the external} control

\section{ABSTRACT}

The purpose of this study is to verify which the professionals' perception that act in the external control on the controllership in the municipal public system, approaching organizational, structural and managerial aspects. The used methodology is characterized as for the objectives as exploratory; the used procedures were bibliographical researches and survey. The research was conducted by questionnaire sent to the professionals that act in an organ of external control in the South of the country. The results demonstrate that the professionals who act in the external control understand that controllership in the municipal ambient should be treated with an organ of staff, that their functions should have managerial nature and that, in the researched people's opinions, the implantation of the municipal controllership is configured with an evolution in the form of administering the system municipal public taking such entities to improve the application of the existent public resources and, consequently, their performance.

Key words: Controllership. Municipal Controllership. External Control.

\section{INTRODUÇÃO}

As administrações públicas municipais nos últimos anos vêm convivendo com inúmeras mudanças de ordem financeira, estrutural e comportamental. Seus gestores precisam, da melhor forma possível, conciliar as alterações observadas no ambiente com o atendimento as necessidades da população por serviços públicos.

As mudanças financeiras decorrem da escassez dos recursos necessários para custear os serviços públicos; a estrutural, por fatores econômicos e sociais, os quais a população em geral enfrenta, levando os entes públicos municipais a expandirem os atendimentos à coletividade aumentando suas estruturas; e as questões comportamentais referem-se a forma de gerenciar os entes públicos e decorrem, principalmente, das imposições impostas pelas novas legislações, como a Lei de Responsabilidade Fiscal - LRF. Esta nova postura dos gestores públicos está, 
Controladoria pública municipal na perspectiva dos profissionais do controle externo Willson Gerigk, Marcelo Resquetti Tarifa, Lauro Brito de Almeida, Márcia Maria dos Santos Bortolocci

certamente, vinculada também à disseminação da Tecnologia da Informação (TI), o que tem propiciado maior poder de fiscalização aos órgãos de controle externo sobre as administrações públicas municipais, contribuindo para essa mudança de postura.

Além destes fatores, Catelli e Santos (2004) enfatizam que a condução da gestão pública torna-se cada vez mais uma preocupação cotidiana dos cidadãos. Estes, estimulados a participar da vida sociopolítica, são continuamente informados pelos meios de comunicação sobre os impactos dos planos, das políticas, dos orçamentos, dos déficits e superávits dos governos na qualidade de vida de cada membro e setor da sociedade. Com isso, demandam para que cada vez mais os gestores públicos não apenas se atenham com disciplina aos limites dos escassos recursos orçados, mas otimizem a aplicação desses recursos em políticas que atendam efetivamente as necessidades da sociedade, exigindo planejamento e controle pautados em bases sólidas e confiáveis de informações sobre a execução dos orçamentos municipais e do equilíbrio das contas públicas.

Isto posto, diante dos diversos fatores incorporados ao cotidiano das administrações públicas municipais, o presente estudo tem como questão orientadora: qual a visão dos profissionais que atuam no controle externo sobre a controladoria no ambiente municipal? Assim, o objetivo geral da presente pesquisa é verificar a percepção dos profissionais que atuam no controle externo sobre a controladoria municipal, abordando aspectos organizacionais, estruturais e gerenciais.

O presente estudo é composto de cinco seções. Após essa introdução, abordase o referencial teórico e na seqüência a metodologia utilizada. Na quarta seção são expostos os resultados da pesquisa empírica, e por fim são apresentadas as considerações finais.

\section{FUNDAMENTAÇÃO TEÓRICA}

O desenvolvimento deste estudo requer que sejam abordados conceitos de administração e gestão pública municipal, modelo de gestão dos entes públicos 
Controladoria pública municipal na perspectiva dos profissionais do controle externo Willson Gerigk, Marcelo Resquetti Tarifa, Lauro Brito de Almeida, Márcia Maria dos Santos Bortolocci

Espejo

municipais e a controladoria no ambiente municipal.

\subsection{Administração Pública}

A estrutura político-administrativa do país contempla três níveis de governo: Federal, Estadual, incluindo o Distrito Federal; e o Municipal. Cada um desses níveis de governo busca, por meio de suas estruturas organizacionais, satisfazer as necessidades da coletividade com a criação, realização e expansão dos serviços públicos, que são realizados por intermédio da administração pública. Nesta perspectiva, a administração pública e o governo diferem em seu sentido formal, material e operacional.

A administração pública, em sentido formal, é o conjunto de órgãos instituídos para consecução dos objetivos do governo; em sentido material, é o conjunto das funções necessárias aos serviços públicos em geral; em acepção operacional, é o desempenho perene e sistemático, legal e técnico, dos serviços próprios do Estado ou por ele assumidos em benefício da coletividade (Meirelles, 1995, p.60).

Slomski (2003, p.366) expõe que serviço público é "[...] o conjunto de atividadesmeio e de atividades-fins exercidas ou colocadas à disposição da sociedade, prestadas diretamente, permitidas ou concedidas pelo Estado, visando proporcionar o maior grau possível de bem-estar social da coletividade". O autor salienta, ainda, que:

[...] as atividades-meio têm o objetivo de assegurar os controles internos da administração pública mediante as funções de assessoramento, chefia e dos serviços auxiliares. Já as atividades-fins têm como objetivo assegurar os serviços caracterizados como essenciais, complementares e públicos, cuja finalidade é a de promover o bem- estar social da coletividade [...] em que as atividades-meio dão suporte à realização das atividades fins, objetivo final dos serviços públicos.

Kohama (1996, p.31) expõe que "verifica-se a existência de uma íntima sintonia entre a Administração Pública e o Serviço Público, fazendo pressupor, clara e 
Controladoria pública municipal na perspectiva dos profissionais do controle externo Willson Gerigk, Marcelo Resquetti Tarifa, Lauro Brito de Almeida, Márcia Maria dos Santos Bortolocci

nitidamente, que a execução deste seja feita privativamente por aquela, quer diretamente, quer por delegação". Assim, observa-se que administração pública é a atividade pela qual os gestores públicos buscam satisfazer as necessidades de interesse público, para tanto buscam interpretar as carências e anseios da sociedade e atendê-las por intermédio dos serviços públicos. A administração pública objetiva dar respostas concretas às necessidades da sociedade, gerindo da melhor forma os recursos públicos (humanos, financeiros, econômicos e patrimoniais) disponíveis, visando sua otimização.

\subsection{Gestão pública municipal}

A administração de uma organização é feita mediante a efetiva gestão de seus recursos financeiros, estruturais e de recursos humanos, de acordo com os objetivos e finalidades da entidade. Para Chiavenato (2001), administrar é interpretar os objetivos propostos pela empresa e transformá-los em ação por meio do planejamento, organização, direção e controle de todos os esforços realizados em todas as áreas e em todos os níveis da empresa, a fim de atingir tais objetivos.

A gestão caracteriza-se pela atuação em nível interno da organização, que procura otimizar as relações recursos-operação-produtos/serviços, considerando as variáveis dos ambientes externo e interno que impactam as atividades da entidade, em seus aspectos operacionais, financeiros, econômicos e patrimoniais (Pereira, 2001, p.57). Assim, a gestão atua com o objetivo de maximizar os produtos e/ou serviços gerados pela organização, levando em consideração os eventos endógenos e exógenos aos quais a organização está exposta e que afetam seus resultados. Neste aspecto, o processo de gestão deve assegurar o alcance dos objetivos da organização de forma eficiente e eficaz.

O processo de gestão está intimamente ligado ao modelo de gestão e ao sistema de informação presente na organização, e são elementos fundamentais na busca da eficácia organizacional. O modelo de gestão é delineado com base na missão, crenças e valores da organização, e se caracteriza como sendo um conjunto de 
Controladoria pública municipal na perspectiva dos profissionais do controle externo Willson Gerigk, Marcelo Resquetti Tarifa, Lauro Brito de Almeida, Márcia Maria dos Santos Bortolocci

regras e princípios utilizados pelas organizações em sua administração, considerando sua atividade principal, seus objetivos e as finalidades que levaram à sua criação, os quais devem estar contemplados no modelo de gestão utilizado (Pereira, 2001).

Neste sentido, modelo de gestão é a Carta Magna de uma entidade. Possuem um conjunto de princípios, nem sempre formalizados, que podem ser identificados por meio da observação dos instrumentos de gestão (processo de planejamento e controle, sistema de informação, etc) e das demais práticas organizacionais (Parisi, 2001).

Nas administrações públicas, os instrumentos de gestão estão consubtanciados no Sistema de Planejamento Integrado, o qual contempla o Plano Plurianual - PPA, a Lei de Diretrizes Orçamentárias - LDO e a Lei Orçamentária Anual - LOA (mais conhecida como Orçamento Público), apresentado a seguir (Figura 1).

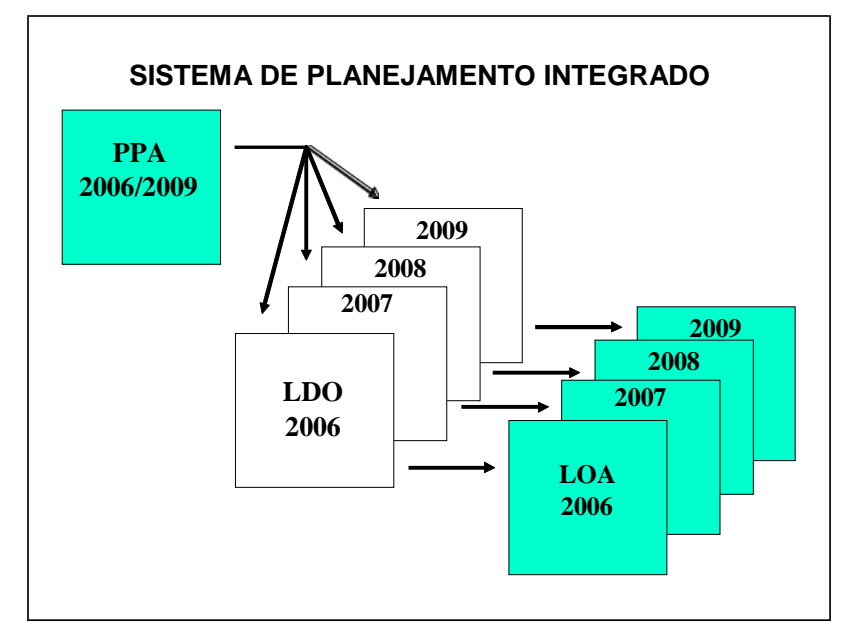

Figura 1 - Instrumentos de gestão das administrações públicas Fonte: Elaborado pelos autores

O Plano Plurianual - PPA conterá as diretrizes, objetivos e metas da administração pública para as despesas de capitais e outras despesas que delas decorram, bem como para as despesas relativas aos programas de duração continuada. O PPA terá duração de quatro anos e configura-se como planejamento de médio prazo nas entidades públicas. 
Controladoria pública municipal na perspectiva dos profissionais do controle externo Willson Gerigk, Marcelo Resquetti Tarifa, Lauro Brito de Almeida, Márcia Maria dos Santos Bortolocci

A Lei de Diretrizes Orçamentárias - LDO, por sua vez, orienta a elaboração da Lei Orçamentária Anual - LOA, e compreende as metas e prioridades da administração pública para o exercício financeiro subseqüente. Desta forma ela estabelece o que será contemplado no orçamento público anual. As diretrizes da LDO são anuais e têm por base o planejamento de médio prazo (PPA).

Por fim, para que a administração pública possa materializar seus objetivos e metas, necessita aprovar a Lei Orçamentária Anual - LOA, conhecido como orçamento público, o qual conterá as metas físicas e financeiras que o ente público pretende realizar no decorrer do exercício financeiro subseqüente, a fim de atender as metas e prioridades estabelecidas na LDO. No orçamento anual será contemplado o programa do governo com suas respectivas ações, devidamente custeado, bem como o montante de receitas que farão frente às despesas consignadas. O orçamento público é o instrumento de execução das metas e objetivos da administração pública para determinado exercício, e é por intermédio dele que o planejamento se concretiza (Figura 2).

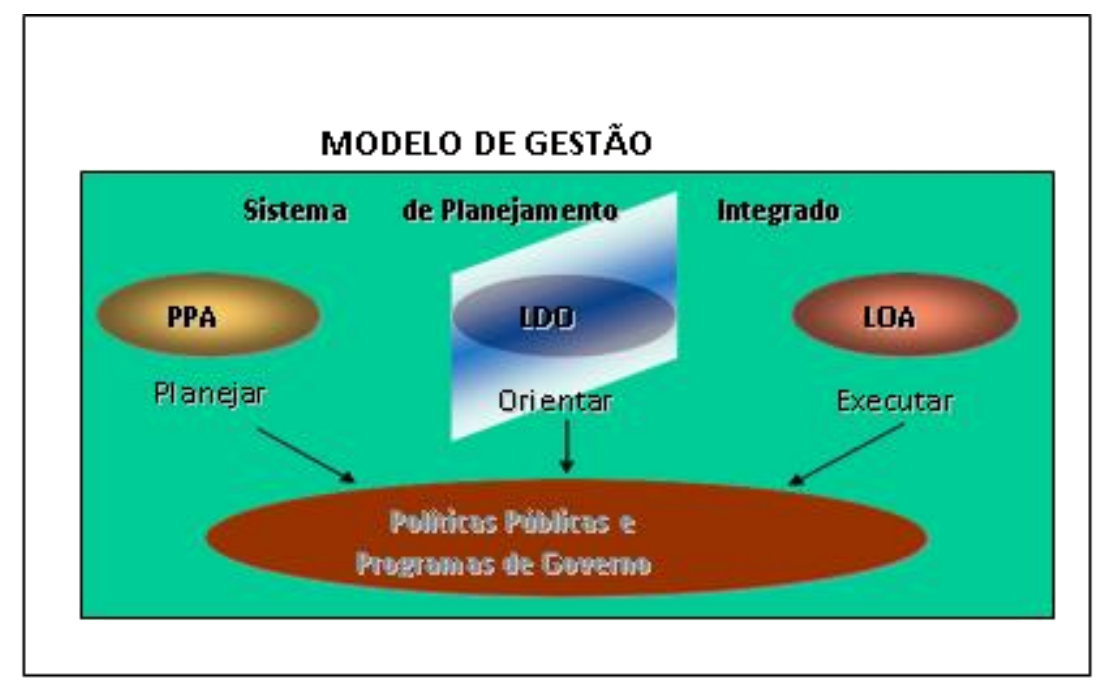

Figura 2 - Funções dos instrumentos de gestão nas administrações públicas Fonte: Elaborado pelos autores

A finalidade precípua das administrações públicas municipais é a prestação de 
Controladoria pública municipal na perspectiva dos profissionais do controle externo Willson Gerigk, Marcelo Resquetti Tarifa, Lauro Brito de Almeida, Márcia Maria dos Santos Bortolocci

serviços públicos locais aos cidadãos. Para tanto utiliza-se do Sistema de Planejamento Integrado (PPA, LDO e LOA), caracterizando o instrumento de gestão das entidades públicas municipais. Os serviços públicos estão contemplados nas políticas públicas e nos programas de governo, estipulados pelo ente público para determinado período de tempo.

Salienta-se que os instrumentos que compõem o modelo de gestão nas entidades públicas têm finalidade específica. O PPA contempla o planejamento de determinado Município para quatro anos; a LDO tem por função orientar a execução do planejamento anteriormente previsto no PPA, e a LOA tem a incumbência de executar o planejamento. Assim, têm-se os programas e ações planejadas pelas administrações públicas, das quais resultam os serviços públicos necessários para atender a coletividade, previstos para determinado período de tempo.

\subsection{Controladoria municipal}

As administrações públicas necessitam de formas alternativas de controles, não apenas controles formais, que objetivam atender estritamente as determinações legais, mas também de controles gerenciais, que atendam as exigências legais e priorizem o atendimento dos resultados, detectando antecipadamente os problemas e corrigindo as possíveis distorções, fazendo com que a gestão pública cumpra seu papel de forma eficiente e eficaz.

A administração será eficiente quando conseguir realizar as ações governamentais planejadas de forma econômica, ou seja, otimizando os recursos disponíveis. Desta forma, propiciará maiores condições de suprir as necessidades de sua população pela realização de um maior número de ações e/ou programas com menor volume de recursos.

Assim, além de buscar a maximização na aplicação dos recursos públicos disponíveis, o administrador público precisa estar atento a outras peculiaridades que cercam a gestão de um ente público, que são as diversas interferências da legislação constitucional e infra- constitucional, que fazem uma grande distinção entre gerir um 
Controladoria pública municipal na perspectiva dos profissionais do controle externo Willson Gerigk, Marcelo Resquetti Tarifa, Lauro Brito de Almeida, Márcia Maria dos Santos Bortolocci

ente privado e um ente público. Com todos esses desafios os gestores públicos, principalmente, dos municípios de pequeno porte, devem procurar estruturar suas administrações para atingir suas metas e objetivos, sem deixar de cumprir as determinações legais, aplicando os recursos públicos de forma ordenada, para que a população seja cada vez mais beneficiada.

Certamente, dentro dessa necessidade de mudança da política de gestão e, conseqüentemente, da estrutura de funcionamento das administrações públicas municipais, a Controladoria Pública pode ser vista como a resposta a essa nova realidade. Sua implantação e estruturação nos entes públicos municipais tem por objetivo o acompanhamento e colaboração na coordenação de ações com enfoque gerencial, para que os objetivos traçados sejam atingidos, bem como, haja disponibilização de informações de forma clara e objetiva que contribua para a gestão das atividades municipais.

Nesta perspectiva, a controladoria como órgão responsável pela coordenação das informações, busca induzir a eficácia dos resultados pelo conhecimento que envolve a gestão operacional, financeira, econômica e patrimonial das organizações. Assim, a controladoria deve ser vista como um órgão aglutinador e direcionador de esforços dos gestores que conduzam à otimização do resultado global da organização. Figueiredo e Caggiano (1997, p. 26 e 27) corroboram expondo que a controladoria deve "garantir informações adequadas ao processo decisório, colaborando com os gestores na busca da eficácia gerencial".

Almeida et al., (2001, p. 344-345) apresentam uma outra abordagem, a de que a Controladoria pode ser vista sob dois prismas: como ramo de conhecimento e como unidade administrativa, como ilustrado na Figura 3. 
Controladoria pública municipal na perspectiva dos profissionais do controle externo Willson Gerigk, Marcelo Resquetti Tarifa, Lauro Brito de Almeida, Márcia Maria dos Santos Bortolocci

Espejo
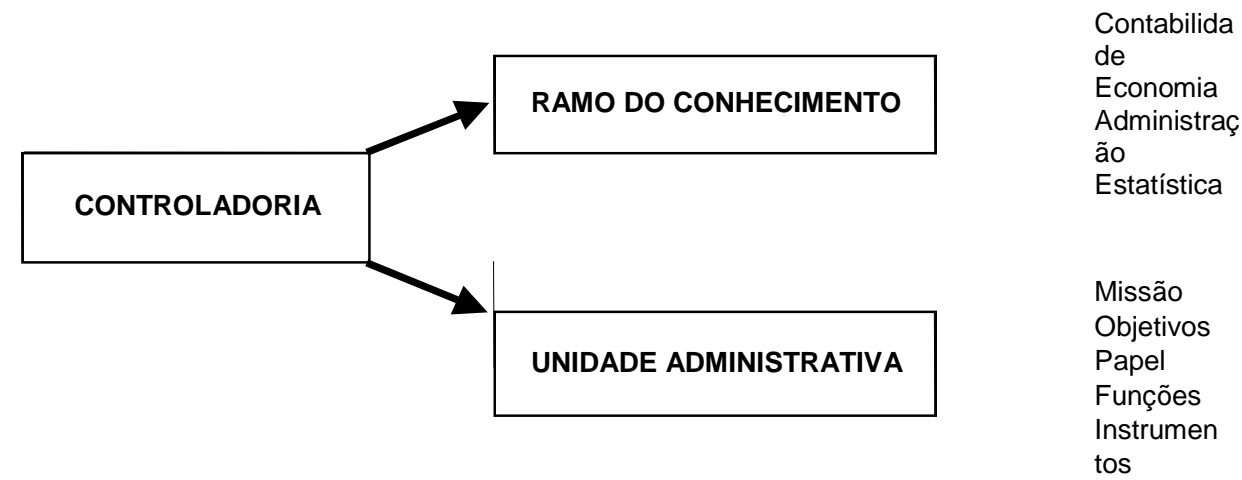

Figura 3 - Abordagem da controladoria no ambiente empresarial Fonte: Almeida, 2007.

Almeida et al., (2001, p. 344-345) esclarecem que:

[...] enquanto ramo de conhecimento, apoiada na Teoria da Contabilidade e numa visão multidisciplinar, é responsável pelo estabelecimento das bases teóricas e conceituais necessárias para a modelagem, construção e manutenção de Sistemas de Informações e Modelo de Gestão Econômica, que supram adequadamente as necessidades informativas dos Gestores e os induzam durante o processo de gestão, quando requerido, a tomarem decisões ótimas. [...] como Unidade Administrativa é responsável pela coordenação e disseminação desta Tecnologia de Gestão - quanto ao conjunto de teoria, conceitos, sistemas de informações - e também, como órgão aglutinador e direcionador de esforços dos demais gestores que conduzam à otimização do resultado global da organização.

A controladoria visa a coordenação da gestão das atividades organizacionais sob a perspectiva sistêmica de coordenar os esforços para conseguir um resultado global, assim como a coordenação do cumprimento da missão da organização e o zelo pela sua continuidade. Para Mosimann e Fisch (1999, p.90), "a missão da controladoria é otimizar os resultados econômicos da organização, para garantir sua continuidade, por meio da integração dos esforços das diversas áreas".

Catelli in (Nakagawa 1995, p.28) expõe que 
Controladoria pública municipal na perspectiva dos profissionais do controle externo Willson Gerigk, Marcelo Resquetti Tarifa, Lauro Brito de Almeida, Márcia Maria dos Santos Bortolocci

[...] independente dos principais objetivos a que se propõe operar uma empresa, haverá sempre a preocupação com o bom andamento de suas atividades, com a utilização dos recursos de forma mais eficiente e econômica, afim de que a mesma possa operar sem desajuste dos recursos, evitando, ao máximo possível, problemas econômicos, humanos, sociais, etc.

Nesse sentido, a controladoria busca atender as necessidades informacionais também das entidades públicas, pela construção e operacionalização de um sistema de informações que atenda suas peculiaridades e coordenando os serviços administrativos, com vistas a auxiliar os gestores municipais em suas decisões, objetivando atingir as metas e resultados almejados, primando pela eficiência e eficácia na entidade.

Para Slomski (2003, p. 373), nos Municípios a controladoria

é o órgão administrativo que gerencia todo o sistema de informações econômico-físico- financeiras, a fim de instrumentalizar os gestores das atividades-fins e das atividades- meio, para a correta mensuração de resultados econômicos produzidos pelas atividades, produzindo um instrumental para a diminuição da assimetria informacional entre os gestores da coisa pública e a sociedade.

Almeida et al., (2001, p. 346) expõem que a controladoria é por excelência uma área coordenadora das informações sobre a gestão, que não substitui a responsabilidade dos gestores, mas busca induzi-los à otimização dos resultados. Desta forma, a finalidade de se adotar a Controladoria, no âmbito municipal, é responsabilizá-la pelo sistema de informação gerencial e controle da legalidade, visando assegurar que o planejamento proposto seja alcançado. A controladoria tem como objetivos centrais a interação com o Chefe do Executivo, suas Secretarias e Departamentos ou Setores, buscando orientar o caminho a ser seguido pela estrutura administrativa, gerando informações tempestivas sobre o que vem ocorrendo com a entidade, ampliando o leque de opções dos gestores municipais, levando-os a tomarem 
Controladoria pública municipal na perspectiva dos profissionais do controle externo Willson Gerigk, Marcelo Resquetti Tarifa, Lauro Brito de Almeida, Márcia Maria dos Santos Bortolocci

suas decisões da forma mais acertada possível.

A missão da Controladoria Municipal será de atuar como instrumento de ligação entre o Chefe do Poder Executivo Municipal, suas Secretarias, Departamentos e os Órgãos da Administração Indireta e as Entidades sem Fins Lucrativos que auxiliam o Ente Público na prestação de serviços à população, gerando as informações necessárias para se atingir os objetivos e as metas traçadas pela administração.

Conforme afirmativa de Mosimann e Fisch (1999, p. 89), a controladoria "deve esforçar-se para garantir o cumprimento da missão e a continuidade da organização. Seu papel fundamental nesse sentido consiste em coordenar os esforços para conseguir um resultado global sinérgico, isto é, superior à soma dos resultados de cada área". Utilizando-a no ente público, direciona-se a "rota" a ser seguida pela estrutura administrativa por intermédio da geração de informações tempestivas sobre a municipalidade, tanto em nível interno quanto externo.

\section{METODOLOGIA}

Metodologia é o conjunto de procedimentos utilizados pelos investigadores que inclui estratégias, abordagens ou posturas metodológicas, métodos explícitos ou não, técnicas e instrumentos de coleta de dados. Todas as acepções dadas à metodologia traduzem mais ou menos explicitamente o caminho seguido pelo investigador (Bufrem, 2006).

O objetivo da presente pesquisa é identificar a percepção que os profissionais, atuantes no controle externo dos órgãos públicos estaduais e municipais, têm sobre a controladoria no ambiente público municipal, sob os aspectos organizacionais, estruturais e gerenciais. Para atingir os objetivos propostos, a metodologia utilizada está a seguir caracterizada quanto aos objetivos e quanto à abordagem do problema.

\subsection{Caracterização da pesquisa}

Diante do objetivo geral proposto, a pesquisa classifica-se como exploratória, fato este que ocorre quando há pouco conhecimento sobre a temática a ser abordada. Por meio do 
Controladoria pública municipal na perspectiva dos profissionais do controle externo Willson Gerigk, Marcelo Resquetti Tarifa, Lauro Brito de Almeida, Márcia Maria dos Santos Bortolocci

Espejo

estudo exploratório, busca-se conhecer com maior profundidade o assunto, de modo a torná-lo mais claro ou construir questões importantes para a condução da pesquisa (Raupp; Beuren, 2003, p. 80).

A classificação das pesquisas em exploratórias, descritivas e explicativas é muito útil para o estabelecimento de seu marco teórico, ou seja, para possibilitar uma aproximação conceitual. Todavia, para analisar os fatos do ponto de vista empírico, para confrontar a visão teórica com os dados da realidade, torna-se necessário traçar um modelo conceitual e operativo da pesquisa (Gil, 1991, p. 47). Raupp e Beuren (2003, p.83) ratificam expondo que nas tipologias exploratórias, descritivas e explicativas "[...] enquadram-se o estudo de caso, a pesquisa de levantamento, a pesquisa bibliográfica, a pesquisa documental, a pesquisa participante e a pesquisa experimental".

Quanto à abordagem do problema, destacam-se as pesquisas qualitativa e quantitativa (Raupp; Beuren, 2003, p. 91). Para Lakatos e Marconi (2004, p. 267) a pesquisa qualitativa "[...] preocupa-se em analisar e interpretar aspectos mais profundos, [...]. Fornece análise mais detalhada sobre as investigações [...]". Richardson (1999, p. 80) corrobora expondo que "[...] os estudos que empregam uma metodologia qualitativa podem descrever a complexidade de determinado problema, analisar a interação de certas variáveis, compreender e classificar processos dinâmicos vividos para os grupos sociais". Neste sentido, o presente estudo se enquadra, quanto à abordagem ao problema, como pesquisa qualitativa.

\subsection{Métodos e técnicas}

Os procedimentos utilizados na pesquisa foram: pesquisa bibliográfica e pesquisa de levantamento ou survey. Por ser de natureza teórica, a pesquisa bibliográfica é parte obrigatória, "haja vista que é por meio dela que se toma conhecimento sobre a produção científica existente. [...]. Por meio dessas bibliografias reúnem-se conhecimentos sobre a temática pesquisada" (Raupp; Beuren, 2003, p. 8687). 
Controladoria pública municipal na perspectiva dos profissionais do controle externo Willson Gerigk, Marcelo Resquetti Tarifa, Lauro Brito de Almeida, Márcia Maria dos Santos Bortolocci

A pesquisa de levantamento ou survey é baseada na solicitação direta de informações a um grupo de pessoas acerca do problema estudado para, em seguida, mediante análise das informações, obter as conclusões sobre os dados coletados (Gil, 1991). Com relação ao instrumento utilizado na pesquisa de levantamento, este foi um questionário contendo perguntas objetivas e também perguntas estruturadas na escala do tipo Likert. Quanto à escala, foram apresentadas perguntas aos respondentes com determinadas situações sobre a controladoria municipal e as opções de respostas foram: "concordo totalmente", "concordo parcialmente", "indiferente", "discordo parcialmente" e "discordo totalmente". Antes da aplicação do questionário, realizou-se pré-teste do questionário com três possíveis respondentes, que atuam junto ao controle externo, para validar 0 instrumento de pesquisa, os quais o consideraram-no satisfatório.

Para Colauto e Beuren (2003, p. 118), população ou universo da pesquisa são "[...] a totalidade de elementos distintos que possui certa paridade nas características definidas para determinado estudo". As pesquisas, no campo das ciências sociais, abarcam um universo de elementos consideravelmente extenso, o que torna inviável considerá-los em sua totalidade. Por essa razão um estudo científico pode buscar a identificação dessas relações e sequências repetitivas mediante estudo amostral, isto é, utilizando frações ou uma pequena parte dos elementos de um universo da pesquisa (Colauto; Beuren, 2003, p. 120). Para Gil (1991), na amostragem por acessibilidade, o pesquisador apenas obtém os elementos a que tem maior facilidade de acesso, admitindo que eles possam efetivamente representar de forma adequada à sociedade.

A pesquisa foi efetuada junto a um órgão de controle externo de um Estado da Região Sul do Brasil. Foram aplicados 63 (sessenta e três) questionários junto aos profissionais que atuam na fiscalização de municípios com até 20.000 habitantes, dos quais foram retornados 42 (quarenta e dois), que representam $66,66 \%$ da população pesquisada, constituindo-se na amostra da pesquisa. Os resultados apresentam a posição dos profissionais pesquisados e não podem ser extrapolados como percepção do órgão a que pertencem. 


\section{RESULTADOS E ANÁLISE DA PESQUISA EMPÍRICA}

Após a coleta dos dados da pesquisa por intermédio dos questionários, efetuouse a tabulação destes com o objetivo de apresentar e analisar os resultados encontrados. Os primeiros resultados abordados referem-se às características dos respondentes, constituída de formação acadêmica, área de formação acadêmica, tempo de atuação na área pública e no controle externo, que representam as questões de 1 a 4 , as quais são demonstradas nas Tabelas a seguir.

Tabela 1 - Formação acadêmica dos respondentes

\begin{tabular}{|c|c|c|}
\hline \multicolumn{3}{|c|}{ Número de respondentes } \\
\hline Formação acadêmica & Quantidade & Percentual (\%) \\
\hline Graduação & 21 & 50 \\
\hline Especialização & 12 & 29 \\
\hline Mestrado & 7 & 17 \\
\hline Doutorado & 2 & 5 \\
\hline Total & 42 & 100 \\
\hline
\end{tabular}

Fonte: Elaborada pelos autores

Quanto à formação acadêmica dos respondentes, 50\% possuem graduação; $29 \%$ tem especialização; $17 \%$ tem mestrado e $5 \%$ doutorado. Este resultado demonstra que metade dos respondentes tem pós-graduação, e que, $22 \%$ destes, ou seja, nove, tem pós-graduação stricto sensu, percentual próximo dos respondentes que possuem pós-graduação lato sensu. Fica evidenciado, que os profissionais que atuam no controle externo buscam aprimorar seus conhecimentos também no ambiente acadêmico. 
Controladoria pública municipal na perspectiva dos profissionais do controle externo Willson Gerigk, Marcelo Resquetti Tarifa, Lauro Brito de Almeida, Márcia Maria dos Santos Bortolocci

Tabela 2 - Área de formação acadêmica dos respondentes

\begin{tabular}{|c|c|c|}
\hline \multicolumn{2}{|c|}{ Número de respondentes } \\
\hline Área de formação acadêmica & Quantidade & Percentual (\%) \\
\hline Administração & 3 & 7 \\
\hline Ciências Contábeis & 34 & 81 \\
\hline Economia & 5 & 12 \\
\hline Total & 42 & 10 \\
\hline
\end{tabular}

Fonte: Elaborada pelos autores

Em relação à formação acadêmica dos respondentes, os resultados demonstram que $81 \%$ dos respondentes são formados em ciências contábeis; $12 \%$ na área de economia e 7\% na área de administração. Como as atividades desenvolvidas requerem vasto conhecimento sobre a contabilidade pública e suas especificidades, é natural a grande proporção evidenciada de formação acadêmica na área de contabilidade, demonstrando a consolidação da área junto ao controle externo.

Outra importante variável pesquisada foi o tempo de atuação dos profissionais, tanto na área pública como no próprio órgão de controle externo, o que é apresentado nas Tabelas 3 e 4, a seguir.

Tabela 3 - Tempo de atuação dos respondentes na área pública

\begin{tabular}{|c|c|c|}
\hline \multicolumn{2}{|c|}{ Número de respondentes } \\
\hline Tempo da atuação na área & Quantidade & Percentual (\%) \\
\hline Até 5 anos & 7 & 17 \\
\hline De 5 a 10 anos & 18 & 43 \\
\hline Acima de 10 anos & 17 & 40 \\
\hline Total & 42 & 100 \\
\hline
\end{tabular}

Fonte: Elaborada pelos autores

Optou-se por estratificar as respostas, conforme apresentado na Tabela 3; assim os resultados encontrados foram: até 5 anos de atuação na área pública teve 17\%; de 5 a 10 anos apresentou o maior percentual com 43\%; e acima de 10 anos atuando na área pública apresentou 40\%. Estes resultados demonstram que a maioria dos profissionais tem mais de 5 anos de experiência na área pública (83\%), destacando os 
Controladoria pública municipal na perspectiva dos profissionais do controle externo Willson Gerigk, Marcelo Resquetti Tarifa, Lauro Brito de Almeida, Márcia Maria dos Santos Bortolocci

que estão há mais de 10 anos atuando na área (40\%) o que, certamente, garante boa experiência profissional e bom conhecimento sobre os assuntos inerentes aos entes públicos.

Tabela 4 - Tempo de atuação dos respondentes no controle externo

\begin{tabular}{|c|c|c|}
\hline \multicolumn{2}{|c|}{ Número de respondentes } \\
\hline Tempo da atuação no controle externo & Quantidade & Percentual (\%) \\
\hline Até 5 anos & 12 & 29 \\
\hline De 5 a 10 anos & 23 & 55 \\
\hline Acima de 10 anos & 7 & 17 \\
\hline Total & 42 & 100 \\
\hline
\end{tabular}

Fonte: Elaborada pelos autores

A Tabela 4 evidencia o tempo de atuação dos respondentes junto ao órgão de controle externo, sendo que as respostas também foram estratificadas e os resultados encontrados foram que $29 \%$ dos profissionais têm menos que 5 anos atuando no controle externo; $55 \%$ já atuam entre 5 a 10 anos; e 17\% atuam há mais de 10 anos junto ao controle externo. Diante dos objetivos da pesquisa e das informações sobre os respondentes, considera-se que as opiniões expressadas sobre a controladoria no âmbito municipal foram pautadas na boa experiência profissional, adequada qualificação acadêmica, bem como no conhecimento que estes têm sobre os assuntos que envolvem os entes públicos municipais.

O segundo tópico da pesquisa diz respeito à compreensão dos respondentes sobre a estrutura hierárquica da controladoria no ambiente municipal, com população inferior a 20.000 habitantes (Tabelas 5 e 6 ). 
Controladoria pública municipal na perspectiva dos profissionais do controle externo Willson Gerigk, Marcelo Resquetti Tarifa, Lauro Brito de Almeida, Márcia Maria dos Santos Bortolocci

Tabela 5 - Vinculação da Controladoria municipal diretamente ao Prefeito Municipal

\begin{tabular}{lcc}
\hline & \multicolumn{2}{c}{ Número de respondentes } \\
\cline { 2 - 4 } Percepção quanto à subordinação da controladoria & Quantidade \\
\hline & Percentual (\%) \\
Concordo Totalmente & 25 & 60 \\
Concordo parcialmente & 9 & 21 \\
Indiferente & - & 0 \\
Discordo parcialmente & 6 & 14 \\
Discordo totalmente & 2 & 5 \\
\hline \multicolumn{1}{c}{ Total } & 42 & 100 \\
\hline
\end{tabular}

Fonte: Elaborada pelos autores

Os resultados demonstram que $60 \%$ dos respondentes defendem que a controladoria deve estar subordinada exclusivamente ao Prefeito Municipal para evitar conflitos e coerção das Secretarias ou demais órgãos municipais, em virtude de se encontrarem no mesmo nível hierárquico. Esta percepção é corroborada com as respostas apresentadas na Tabela 6.

Tabela 6 - A controladoria municipal como secretaria municipal ou órgão equivalente

\begin{tabular}{|c|c|c|}
\hline \multicolumn{3}{|c|}{ Número de respondentes } \\
\hline Percepção quanto à hierarquia da controladoria & Quantidade & Percentual (\%) \\
\hline Concordo totalmente & - & 0 \\
\hline Concordo parcialmente & 2 & 5 \\
\hline Indiferente & - & 0 \\
\hline Discordo parcialmente & 12 & 29 \\
\hline Discordo totalmente & 28 & 67 \\
\hline Total & 42 & 100 \\
\hline
\end{tabular}

Fonte: Elaborada pelos autores

Os resultados demonstram que $96 \%$ dos respondentes não concordam com a estrutura da controladoria municipal como um órgão equivalente à Secretaria Municipal, sendo que destes, $67 \%$ discordam totalmente.

O objetivo das questões apresentadas nas Tabelas 5 e 6 era observar a compreensão dos respondentes em relação à estrutura hierárquica versus a resolução dos conflitos de poder. Os resultados indicam que os respondentes não acreditam que a 
Controladoria pública municipal na perspectiva dos profissionais do controle externo Willson Gerigk, Marcelo Resquetti Tarifa, Lauro Brito de Almeida, Márcia Maria dos Santos Bortolocci

controladoria deva ser considerada como uma unidade hierárquica equivalente às secretarias municipais, tendo em vista a dificuldade de estabelecimento de controles e exigências, por estarem no mesmo nível hierárquico de autoridade dentro da estrutura administrativa. Para os pesquisados, a controladoria deve estar subordinada diretamente ao Prefeito Municipal com autoridade e isenção em relação aos demais órgãos e departamentos componentes da estrutura organizacional.

Em continuação ao tópico da estrutura da controladoria, identifica-se na tabela a seguir, a percepção dos respondentes quanto à função da controladoria. Dentre as funções relacionadas no questionário, nenhuma delas possui $50 \%$ de aceitação como função da controladoria.

Tabela 7 - Departamentos ou setores que devem estar hierarquicamente subordinados a controladoria municipal

\begin{tabular}{|c|c|c|c|c|c|c|c|c|c|c|}
\hline \multirow[b]{2}{*}{ Departamento/Setor } & \multicolumn{2}{|c|}{$\begin{array}{l}\text { Concordo } \\
\text { Totalmente }\end{array}$} & \multicolumn{2}{|c|}{$\begin{array}{c}\text { Concordo } \\
\text { Parcialmente }\end{array}$} & \multicolumn{2}{|c|}{ Indiferente } & \multicolumn{2}{|c|}{$\begin{array}{c}\text { Discordo } \\
\text { Parcialmente }\end{array}$} & \multicolumn{2}{|c|}{$\begin{array}{l}\text { Discordo } \\
\text { Totalmente }\end{array}$} \\
\hline & $\mathbf{n}$ & $\%$ & $\mathbf{n}$ & $\%$ & $\mathbf{n}$ & $\%$ & $\mathbf{n}$ & $\%$ & $\mathbf{n}$ & $\%$ \\
\hline Auditoria Interna & 18 & $43 \%$ & 14 & $33 \%$ & 0 & 0 & 7 & $17 \%$ & 3 & $7 \%$ \\
\hline Planejamento Municipa & 10 & $24 \%$ & 13 & $31 \%$ & 0 & 0 & 14 & $33 \%$ & 5 & $12 \%$ \\
\hline Execucão & 13 & $31 \%$ & 8 & $19 \%$ & 0 & 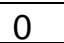 & 15 & $36 \%$ & 6 & $14 \%$ \\
\hline Custos & 8 & $19 \%$ & 14 & $33 \%$ & 0 & C & 13 & $31 \%$ & 7 & $17 \%$ \\
\hline Contabilidade & 5 & $12 \%$ & 11 & $26 \%$ & 0 & 0 & 7 & $17 \%$ & 19 & $45 \%$ \\
\hline Tesouraria & 5 & $12 \%$ & 11 & $26 \%$ & 0 & 0 & 7 & $17 \%$ & 19 & $45 \%$ \\
\hline Compras e Licitação & 4 & $10 \%$ & 9 & $21 \%$ & 0 & 0 & 11 & $26 \%$ & 18 & $43 \%$ \\
\hline Tributação & 3 & $7 \%$ & 13 & $31 \%$ & 0 & 0 & 8 & $19 \%$ & 18 & $43 \%$ \\
\hline Patrimônio & 3 & $7 \%$ & 11 & $26 \%$ & 0 & 0 & 18 & $43 \%$ & 10 & $24 \%$ \\
\hline Convé & 2 & $5 \%$ & 7 & $17 \%$ & 0 & C & 15 & $36 \%$ & 18 & $43 \%$ \\
\hline Recursos Humanos & 1 & $2 \%$ & 12 & $29 \%$ & 0 & 0 & 16 & $38 \%$ & 13 & $31 \%$ \\
\hline
\end{tabular}

Fonte: Elaborada pelos autores

A Auditoria Interna, atividade compreendida como controle interno da organização municipal, foi aceita por $43 \%$ dos respondentes como função da controladoria; 33\% como aceitação parcial e 17\% como discordância parcial. Ao solicitar a indicação em que setor a auditoria interna dever estar vinculada (Tabela 8), $43 \%$ indicaram que deve estar vinculada à controladoria municipal, enquanto $40 \%$ indicam que deve estar subordinada ao Gabinete Municipal; 2\% à Secretaria de 
Controladoria pública municipal na perspectiva dos profissionais do controle externo Willson Gerigk, Marcelo Resquetti Tarifa, Lauro Brito de Almeida, Márcia Maria dos Santos Bortolocci

Finanças e $14 \%$ à Secretaria de Administração. Assim, provavelmente quem não indicou a auditoria interna como subordinada hierarquicamente a controladoria, indicou como atividades vinculadas a órgãos afins. A indicação da auditoria como função da controladoria é corroborada também pela indicação de $67 \%$ dos respondentes do controle interno como atividade subordinada à controladoria, que pode ser observado na Tabela 8, a seguir.

Tabela 8 - Subordinação dos departamentos ou setores na estrutura organizacional

\begin{tabular}{|c|c|c|c|c|c|c|c|c|c|c|c|c|}
\hline \multicolumn{1}{c}{$\begin{array}{c}\text { Controladoria Secretaria de Secretaria de Secretaria de Prefeito Outras Secret. } \\
\text { Municipal }\end{array}$} \\
\begin{tabular}{|c|c|c|c|c|c|c|c|c|c|c|c|}
\hline Administração \\
Departamento/Setor
\end{tabular} & $\mathbf{n}$ & $\%$ & $\mathbf{n}$ & $\%$ & $\mathbf{n}$ & $\%$ & $\mathbf{n}$ & $\%$ & $\mathbf{n}$ & $\%$ & $\mathbf{n}$ & $\%$ \\
\hline Auditoria Interna & 18 & $43 \%$ & 6 & $14 \%$ & 1 & $2 \%$ & 0 & $0 \%$ & 17 & $40 \%$ & 0 & $0 \%$ \\
\hline $\begin{array}{c}\text { Planejamento } \\
\text { Municipal }\end{array}$ & 4 & $10 \%$ & 38 & $90 \%$ & 0 & $0 \%$ & 0 & $0 \%$ & 0 & $0 \%$ & 0 & $0 \%$ \\
\hline $\begin{array}{c}\text { Execução } \\
\text { orçamentária }\end{array}$ & 5 & $12 \%$ & 0 & $0 \%$ & 37 & $88 \%$ & 0 & $0 \%$ & 0 & $0 \%$ & 0 & $0 \%$ \\
\hline Custos & 0 & $0 \%$ & 8 & $19 \%$ & 11 & $26 \%$ & 0 & $0 \%$ & 23 & $55 \%$ & 0 & $0 \%$ \\
\hline Contabilidade & 0 & $0 \%$ & 7 & $17 \%$ & 5 & $12 \%$ & 0 & $0 \%$ & 30 & $71 \%$ & 0 & $0 \%$ \\
\hline Tesouraria & 2 & $5 \%$ & 0 & $0 \%$ & 40 & $95 \%$ & 0 & $0 \%$ & 0 & $0 \%$ & 0 & $0 \%$ \\
\hline Compras e Licitação & 8 & $19 \%$ & 0 & $0 \%$ & 34 & $81 \%$ & 0 & $0 \%$ & 0 & $0 \%$ & 0 & $0 \%$ \\
\hline Tributação & 13 & $31 \%$ & 0 & $0 \%$ & 29 & $69 \%$ & 0 & $0 \%$ & 0 & $0 \%$ & 0 & $0 \%$ \\
\hline Patrimônio & 3 & $7 \%$ & 34 & $81 \%$ & 5 & $12 \%$ & 0 & $0 \%$ & 0 & $0 \%$ & 0 & $0 \%$ \\
\hline Convênio & 20 & $48 \%$ & 12 & $29 \%$ & 10 & $24 \%$ & 0 & $0 \%$ & 0 & $0 \%$ & 0 & $0 \%$ \\
\hline Recursos Humanos & 1 & $2 \%$ & 41 & $98 \%$ & 0 & $0 \%$ & 0 & $0 \%$ & 0 & $0 \%$ & 0 & $0 \%$ \\
\hline
\end{tabular}


Percebe-se que as demais funções foram discordantes enquanto função da controladoria (Tabela 7). Os resultados indicam que a controladoria não deve ser tratada como um órgão executor das atividades financeiras, indicando que este órgão é visto como staff e tem como objetivo coordenar os resultados da organização. Essa constatação é corroborada com o grande número de indicação, por parte dos respondentes, que as áreas possíveis de serem contempladas na controladoria são as áreas de auditoria, planejamento municipal e execução orçamentária. Esses resultados são ratificados quando se procurou, por meio da tabela 8 , identificar o setor a que deve estar subordinada cada atividade vinculada às funções financeiras da organização pública.

Observa-se que as funções vinculadas direta ou indiretamente às atividades financeiras dos municípios são compreendidas pelos respondentes como subordinadas à alguma Secretaria ou órgão equivalente. Assim, os resultados sugerem que a controladoria é vista como órgão de staff, com a função de coordenação das ações e da sinergia da organização, trabalhando subordinada exclusivamente a Prefeito Municipal para evitar conflitos de hierarquia funcional.

Pela perspectiva da maioria dos respondentes, as funções de planejamento municipal devem estar vinculadas à Secretaria de Planejamento ou órgão equivalente; as funções de Recursos Humanos, Patrimônio e Compras e Licitação, devem estar vinculadas à Secretaria de Administração ou órgão equivalente; e as funções de contabilidade, tributação, execução orçamentária, tesouraria, custos e controle de convênios devem estar vinculados a Secretaria de Finanças ou órgão equivalente. Estes resultados indicam que a execução das atividades relacionadas às despesas $\mathrm{e}$ receitas da administração pública municipal não fazem parte das atividades da controladoria pela perspectiva do controle externo.

Isto é corroborado novamente pelos respondentes (Tabela 9), quando fica evidenciado que, em linhas gerais, a execução e controle financeiro é feita pela contabilidade e não pela controladoria. 
Tabela 9 - Setores que devem estar hierarquicamente subordinados a contabilidade municipal

\begin{tabular}{|c|c|c|c|c|c|c|c|c|c|c|}
\hline & \multicolumn{2}{|c|}{$\begin{array}{l}\text { Concordo } \\
\text { Totalmente }\end{array}$} & \multicolumn{2}{|c|}{$\begin{array}{l}\text { Concordo } \\
\text { Parcialmente }\end{array}$} & \multirow{2}{*}{\multicolumn{2}{|c|}{$\begin{array}{c}\text { Indiferente } \\
\%\end{array}$}} & \multicolumn{2}{|c|}{$\begin{array}{l}\text { Discordo } \\
\text { Parcialmente }\end{array}$} & \multicolumn{2}{|c|}{$\begin{array}{l}\text { Discordo } \\
\text { Totalmente }\end{array}$} \\
\hline Dpto/Setor & $\mathrm{n}$ & $\%$ & $\mathrm{n}$ & $\%$ & & & & $\%$ & $\mathrm{n}$ & $\%$ \\
\hline Tesouraria & 37 & 88 & 5 & 12 & - & 0 & - & 0 & - & 0 \\
\hline Execução & 29 & 69 & 9 & 21 & - & 0 & 4 & 10 & - & 0 \\
\hline Convênios & 28 & 67 & 13 & 31 & - & 0 & 2 & 5 & - & 0 \\
\hline Custos & 23 & 55 & 11 & 26 & - & 0 & 7 & 17 & 1 & 2 \\
\hline Patrimônio & 21 & 50 & 14 & 33 & - & 0 & 7 & 17 & - & 0 \\
\hline
\end{tabular}

Fonte: Elaborada pelos autores

Desta forma, na percepção dos respondentes, a contabilidade não deve ser confundida com a controladoria, embora o controle interno seja um dos instrumentos de controle. Enquanto a contabilidade deve estar vinculada à Secretaria de Finanças ou órgão equivalente, a controladoria deve estar subordinada ao Prefeito Municipal. Este resultado, mais uma vez, corrobora com a visão de controladoria como órgão de staff. Interessante observar que os respondentes não se mostraram isentos nas respostas, indicando a opção de indiferente. Todos os respondentes concordaram ou não com a apresentação das questões.

Enfocando, especificamente, a controladoria no ambiente municipal, foi questionado aos profissionais que tipo de informações a controladoria municipal deveria gerar para cumprir com suas funções, os resultados são apresentados na Tabela 10. 
Tabela 10 - Informações geradas pela controladoria municipal segundo a visão dos profissionais do controle externo

\begin{tabular}{|c|c|c|c|c|c|c|c|c|c|c|}
\hline \multirow[t]{2}{*}{$\begin{array}{l}\text { Tipo de Informação gerada } \\
\text { pela controladoria municipal } \\
\text { para atender suas funções }\end{array}$} & \multicolumn{2}{|c|}{$\begin{array}{l}\text { Concordo } \\
\text { Total. } \\
\end{array}$} & \multicolumn{2}{|c|}{$\begin{array}{l}\text { Concordo } \\
\text { Parcial. }\end{array}$} & \multicolumn{2}{|c|}{ Indiferente } & \multicolumn{2}{|c|}{$\begin{array}{l}\text { Discordo } \\
\text { Parcial. }\end{array}$} & \multicolumn{2}{|c|}{$\begin{array}{l}\text { Discordo } \\
\text { Total. }\end{array}$} \\
\hline & $\mathbf{n}$ & $\%$ & $\mathbf{n}$ & $\%$ & $\mathbf{n}$ & $\%$ & $\mathbf{n}$ & $\%$ & $\mathbf{n}$ & $\%$ \\
\hline Gerencial & 42 & $100 \%$ & 0 & $0 \%$ & 0 & $0 \%$ & 0 & $0 \%$ & 0 & $0 \%$ \\
\hline Eficiência da Gestão Municipal & 38 & $90 \%$ & 4 & $10 \%$ & 0 & $0 \%$ & 0 & $0 \%$ & 0 & $0 \%$ \\
\hline Financeiras & 35 & $83 \%$ & 7 & $17 \%$ & 0 & $0 \%$ & 0 & $0 \%$ & 0 & $0 \%$ \\
\hline Orçamentárias & 31 & $74 \%$ & 6 & $14 \%$ & 0 & $0 \%$ & 4 & $10 \%$ & 1 & $2 \%$ \\
\hline Custos & 29 & $69 \%$ & 10 & $24 \%$ & 0 & $0 \%$ & 3 & $7 \%$ & 0 & $0 \%$ \\
\hline Estrutural & 15 & $36 \%$ & 14 & $33 \%$ & 0 & $0 \%$ & 5 & $7 \%$ & 8 & $19 \%$ \\
\hline Legal & 12 & $29 \%$ & 22 & $52 \%$ & 0 & $0 \%$ & 6 & $12 \%$ & 2 & $5 \%$ \\
\hline Patrimonial & 12 & $29 \%$ & 19 & $45 \%$ & 0 & $0 \%$ & 9 & $14 \%$ & 2 & $5 \%$ \\
\hline
\end{tabular}

Fonte: Elaborada pelos autores

Pelas respostas verifica-se que para os profissionais que atuam no controle externo, a controladoria deve ater-se na geração de informações relacionadas às questões que envolvem a administração do ente público, ou seja, vinculadas a questão gerencial, pois $100 \%$ dos respondentes concordam totalmente que as informações devem ser gerenciais; $90 \%$ concordam totalmente e 10\% concordam parcialmente que as informações devem versar sobre a eficiência da gestão municipal; 83\% concordam totalmente e $17 \%$ parcialmente que as informações sejam financeiras; $74 \%$ concordam totalmente que devem ser geradas informações orçamentárias e 14\% concordam parcialmente com a questão; $93 \%$ dos respondentes concordam totalmente ou parcialmente que devem ser geradas informações sobre custo.

As informações que versam sobre estrutura dos entes públicos, aspectos legais e patrimoniais, foram as que receberam menos percentuais de concordância irrestrita e maiores percentuais de discordância, levando a interpretação de que as informações a serem geradas pela controladoria municipal devem auxiliar na gestão dos entes públicos, ou seja, com caráter gerencial, sem esquecer dos aspectos legais e formais que os órgãos públicos estão envoltos.

Visando conhecer a percepção dos profissionais que atuam no controle externo 
Controladoria pública municipal na perspectiva dos profissionais do controle externo Willson Gerigk, Marcelo Resquetti Tarifa, Lauro Brito de Almeida, Márcia Maria dos Santos Bortolocci

Espejo

sobre possíveis mudanças na forma de gerir os entes públicos municipais com população até 20 mil habitantes, foram formuladas oito perguntas envolvendo a implantação da controladoria municipal, sendo os resultados apresentados na tabela a seguir.

Tabela 11 - Visão dos profissionais do controle externo sobre gestão no ambiente municipal com a implantação da controladoria municipal

\begin{tabular}{|c|c|c|c|c|c|c|c|c|c|c|}
\hline \multirow[b]{2}{*}{ Com a implantação da Controladoria Municipal } & \multicolumn{2}{|c|}{$\begin{array}{l}\text { Concordo } \\
\text { Total. }\end{array}$} & \multicolumn{2}{|c|}{$\begin{array}{l}\text { Concordo } \\
\text { Parcial. }\end{array}$} & \multicolumn{2}{|c|}{ Indiferente } & \multicolumn{2}{|c|}{$\begin{array}{l}\text { Discordo } \\
\text { Parcial. }\end{array}$} & \multicolumn{2}{|c|}{$\begin{array}{l}\text { Discordo } \\
\text { Total. }\end{array}$} \\
\hline & $\mathbf{n}$ & $\%$ & $\mathbf{n}$ & $\%$ & $\mathbf{n}$ & $\%$ & $\mathbf{n}$ & $\%$ & $\mathbf{n}$ & $\%$ \\
\hline $\begin{array}{c}\text { As adm. municipais podem melhorar a aplicação } \\
\text { dos recursos públicos e consequentemente } \\
\text { melhorar seu desempenho }\end{array}$ & 42 & $100 \%$ & 0 & $0 \%$ & 0 & $0 \%$ & 0 & $0 \%$ & 0 & $0 \%$ \\
\hline $\begin{array}{l}\text { Configura-se uma evolução na forma de } \\
\text { administrar os entes públicos municipais }\end{array}$ & 42 & $100 \%$ & 0 & $0 \%$ & 0 & $0 \%$ & 0 & $0 \%$ & 0 & $0 \%$ \\
\hline $\begin{array}{l}\text { A execução e o cumprimento das metas } \\
\text { estabelecidas nos instrumentos de planejamento } \\
\text { públicos seriam melhoradas }\end{array}$ & 41 & $98 \%$ & 1 & $2 \%$ & 0 & $0 \%$ & 0 & $0 \%$ & 0 & $0 \%$ \\
\hline $\begin{array}{c}\text { Fica facilitada a implantação da cultura de } \\
\text { controle interno ficando ela } \\
\text { responsável por avaliar os procedimentos } \\
\text { realizados pelos órgãos } \\
\text { integrantes da administração municipal }\end{array}$ & 38 & $90 \%$ & 4 & $10 \%$ & 0 & $0 \%$ & 0 & $0 \%$ & 0 & $0 \%$ \\
\hline $\begin{array}{l}\text { Fica facilitada a implantação do sistema de } \\
\text { custos na adm. Púbica municipal }\end{array}$ & 38 & $90 \%$ & 2 & $5 \%$ & 0 & $0 \%$ & 0 & $0 \%$ & 0 & $0 \%$ \\
\hline $\begin{array}{l}\text { Pode-se promover a diminuição da assimetria } \\
\text { informacional } \\
\text { entre o ente púbico municipal e a sociedade }\end{array}$ & 32 & $76 \%$ & 8 & $19 \%$ & 0 & $0 \%$ & 2 & $5 \%$ & 0 & $0 \%$ \\
\hline $\begin{array}{c}\text { As discussões sobre a elaboração do PPA, da } \\
\text { LDO e da LOA seriam melhoradas no ambiente } \\
\text { municipal }\end{array}$ & 29 & $69 \%$ & 8 & $19 \%$ & 0 & $0 \%$ & 4 & $10 \%$ & 1 & $2 \%$ \\
\hline $\begin{array}{l}\text { Pode ser facilitada a adoção de medidas que } \\
\text { visem facilitar a participação da população nas } \\
\text { discussões sobre o planejamento municipal }\end{array}$ & 4 & $10 \%$ & 18 & $43 \%$ & 0 & $0 \%$ & 12 & $29 \%$ & 8 & $19 \%$ \\
\hline
\end{tabular}

Fonte: Elaborada pelos autores

Pelas respostas apresentadas, os respondentes entendem com $100 \%$ de concordância incondicional que com a implantação da controladoria municipal pode-se melhorar a aplicação dos recursos públicos e o desempenho das administrações; e que a adoção da controladoria no ambiente municipal é uma evolução na forma de administrar tais entes públicos. A totalidade dos respondentes concordam totalmente ou parcialmente que com a controladoria municipal melhoraria a execução e o cumprimentos das metas 
estabelecidas nos instrumentos de planejamento municipal (PPA, LDO e LOA) e que, também, ficaria facilitada a implantação da cultura de auto-controle ou controle interno.

Para 95\% dos respondentes a controladoria municipal pode facilitar a implantação de sistemas que visem custear os serviços públicos municipais; e, também, pode contribuir para minimizar a assimetria informacional entre o Poder Público Municipal e a sociedade. Já, para $88 \%$ dos respondentes as discussões que envolvem o PPA, a LDO e a LOA, seriam melhoradas com a implantação da controladoria municipal.

Porém, quando questionados se com a controladoria municipal melhoria a participação popular nas discussões sobre o planejamento municipal, pouco mais de $50 \%$ concordam com essa afirmativa, demonstrando que a visão dos profissionais que atuam no controle externo é de que a controladoria deve preocupar-se com questões mais internas de gerenciamento do ente público municipal.

\section{CONSIDERAÇÕES FINAIS}

O presente estudo buscou evidenciar, por meio de pesquisa empírica junto aos profissionais que atuam no controle externo público, qual a percepção destes quando o assunto é a controladoria municipal, enfocando aspectos estruturais, organizacionais e gerenciais, levando em consideração municípios com até 20 mil habitantes.

Diante dos resultados apresentados, verifica-se que para tais profissionais a controladoria no ambiente municipal deve ser tratada com um órgão de staff, estando ela ligada diretamente ao Prefeito Municipal, mantendo independência e hierarquia sobre os demais órgãos, departamentos e setores que venham compor a estrutura organizacional das entidades públicas enfocadas na pesquisa.

Quanto às funções da controladoria no ambiente municipal, os respondentes afirmaram que as questões que envolvem procedimentos operacionais relativos às atividades relacionadas às receitas e despesas não devem fazer parte das atividades da controladoria, mas sim de órgãos superiores como Secretarias e departamentos como a contabilidade, pela perspectiva do controle externo.

Quando à questão envolve os tipos de informações que a controladoria municipal 
deveria gerar para cumprir com suas funções, fica claro por parte dos pesquisados que sua função é de natureza gerencial e as informações devem seguir esta perspectiva, deixando as questões formais e legais para os outros órgãos que estão na estrutura hierárquica do ente público.

Para os profissionais que atuam no controle externo, com a implantação da controladoria municipal, as administrações públicas dos municípios com até 20 mil habitantes facilitariam a utilização dos procedimentos de controle interno, a implementação de sistemas de custos, melhoraria o cumprimento das metas planejadas e a discussão sobre a elaboração dos instrumentos de planejamento na área pública municipal e a diminuição da assimetria informacional entre o Executivo Municipal e a sociedade.

A unanimidade entre os profissionais que atuam no controle externo e respondentes da pesquisa, foi de que a implantação da controladoria no ambiente público municipal é uma evolução na forma de se administrar tais entidades; e que com a controladoria os municípios podem melhorar a aplicação os recursos disponíveis e, assim, melhorar seus desempenhos.

Salienta-se, por fim, que esta pesquisa exprime a opinião dos profissionais que atuam nos órgãos de controle externo, e em nada refletem a opinião das Instituições em que eles atuam, bem como o enfoque da pesquisa refere-se a municípios com até 20 mil habitantes

\section{REFERÊNCIAS}

ALMEIDA, L.B. 2007. Anotações das aulas de controladoria. Mestrado em Contabilidade UFPR. Disciplina: Controladoria. Curitiba.

ALMEIDA, L.B; PARISI, C. e PEREIRA, C.A. 2001. Controladoria. In: CATELLI, A. (Coordenador), Controladoria: uma abordagem da gestão econômica - GECON. São Paulo, Atlas, 343-355 p.

BUFREM, L.S. 2006. Mestrado em Contabilidade UFPR. Disciplina: Metodologia da pesquisa científica. Curitiba. Slide 39. 
CATELLI, A. e SANTOS, E.S. 2004. Mensurando a criação de valor na gestão pública. Revista de Administração Pública-RAP. 38(3):423-449.

CHIAVEnAtO, I. 2001. Teoria Geral da Administração. 6 edª . Rio de Janeiro, Campus, $385 \mathrm{p}$.

COLAUTO, R.D. e BEUREN, I.M. 2003. Coleta, análise e interpretação dos dados. In BEUREN, Ilse Maria (Org.). Como elaborar trabalhos monográficos em contabilidade: teoria e prática. São Paulo, Atlas, p. 117-144.

FIGUEIREDO, S. e CAGGIANO, P.C. 1997. Controladoria teoria e prática. 2 edª . São Paulo, Atlas, $276 \mathrm{p}$. . 2004. Controladoria: teoria e prática, 3eda . São Paulo, Atlas, 320 p. GIL, A.C. 1991. Como elaborar projetos de pesquisa. 3 eda p.

KOHAMA, H. 1996. Contabilidade pública: teoria e prática. 5 eda ${ }^{a}$. São Paulo, Atlas, 388 p. LAKATOS, E.M. e MARCONI, M.A. 2004. Metodologia científica. 4 edª . São Paulo, Atlas, $305 \mathrm{p}$.

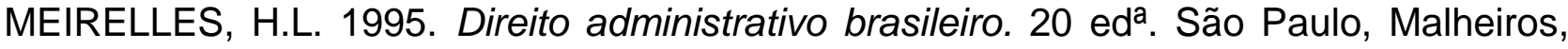
$731 \mathrm{p}$.

MOSIMANN, C.P. e FISCH, S. 1999. Controladoria: seu papel na administração de empresas. 2 ed . São Paulo, Atlas, 144 p.

NAKAGAWA, M. 1995. Introdução à controladoria. São Paulo, Atlas, 104 p.

PEREIRA, C.A. 2001. Ambiente, empresa, gestão e eficácia. In: CATELLI, A. (Coordenador), Controladoria: uma abordagem da gestão econômica - GECON. São Paulo, Atlas, p. 35-80.

PARISI, C. 2001. Ensaio sobre o comportamento organizacional. In: CATELLI, A. (Coordenador), Controladoria: uma abordagem da gestão econômica - GECON. São Paulo, Atlas, p. 268-281.

RAUPP, F.M. e BEUREN, I.M. 2003. Metodologia da pesquisa aplicável às ciências sociais. In: BEUREN, I.M. (Org.). Como elaborar trabalhos monográficos em contabilidade: teoria e prática. São Paulo, Atlas, p. 76-97.

RICHARDSON, R.J. 1999. Pesquisa social: métodos e técnicas. Colaboradores José Augusto de Souza Peres. (et al). São Paulo, Atlas, 334 p. 
Controladoria pública municipal na perspectiva dos profissionais do controle externo Willson Gerigk, Marcelo Resquetti Tarifa, Lauro Brito de Almeida, Márcia Maria dos Santos Bortolocci

SLOMSKI, V. 2003. Manual de contabilidade pública: um enfoque na contabilidade municipal, de acordo com a Lei de Responsabilidade Fiscal. 2ª ed., São Paulo. Atlas, 475 p.

Data de Submissão: 14 /12/2007

Data de Aceite: 15/12/2007 